\title{
SISTEMA DE MONITORAMENTO E DE PREVISÃO AMBIENTAL PORTUÁRIO - PROJETO PILOTO BAÍA DE GUANABARA
}

\author{
Talita Reis Antunes Pereira \\ Universidade Federal Fluminense e gerente do SMAP até 2014. \\ little.talita@gmail.com
}

\begin{abstract}
Resumo
O Centro de Hidrografia da Marinha (CHM) foi responsável pela execução de um projeto de pesquisa e desenvolvimento, financiado pela Financiadora de Estudo e Projetos (FINEP), onde foi desenvolvido um sistema de auxílio à decisão para as atividades portuárias, que levou em consideração as informações ambientais. Trata-se de um sistema de monitoramento das condições ambientais e que também fornece as previsões, oferecendo também ferramentas de fácil visualização das adversidades. O projeto piloto foi desenvolvido para o porto do Rio de Janeiro, devido à facilidade logística com relação à localização do CHM. Este artigo tem o objetivo de detalhar a execução do projeto, bem como apresentar seus resultados e analisar os problemas enfrentados, com intuito de realizar a transferência do conhecimento adquirido durante a execução. O projeto foi um grande aprendizado para a equipe do CHM e trouxe diversos benefícios materiais para a Oorganização.
\end{abstract}

Palavras-Chaves: Gerência de projetos; Monitoramento Ambiental; Modelagem Ambiental; Análise Crítica.

\begin{abstract}
The Centro de Hidrografia da Marinha (CHM) was responsible for the execution of a research and development project, sponsored by the Financiadora de Estudos e Projetos (FINEP), which developed a support decision system for port activities, taking into consideration the environmental information. It is a system for monitoring environmental conditions and provides forecasts for these conditions, also offering special products for adversity cases. The pilot project was developed for the Rio de Janeiro port, considering logistics simplification due to the location of CHM. This article aims to detail the implementation of the project and present their results, analyzing the problems faced while the project was running, providing the exchange of the knowledge acquired during the execution. This project was a great learning experience for CHM and brought many material benefits for the organization.
\end{abstract}

Keywords:

Project Management; Environmental Monitoring; Environmental Modeling; Critical Analysis. 


\section{INTRODUÇÃO}

No cenário da Administração Pública brasileira, de frequentes cortes no Orçamento da União, os Ministérios disputam os recursos financeiros disponíveis, de forma a possibilitar que suas metas para o crescimento socioeconômico e tecnológico sejam atingidas. Diante deste cenário, o Comandante da Marinha (CM) incentiva a busca pela obtenção de recursos financeiros extra orçamentários para o desenvolvimento de projetos e pesquisas de Ciência, Tecnologia e Inovação [9]. Em atendimento às determinações do CM, e seguindo sua visão de futuro em manter-se como um Centro de excelência em hidrografia, meteorologia marítima e oceanografia operacional, contribuindo assim para o desenvolvimento Marítimo, Científico, Social e Econômico do País [7], o Centro de Hidrografia da Marinha (CHM) está constantemente à procura de iniciativas de fomento para o desenvolvimento de projetos e pesquisas que venham a contribuir para o aprimoramento das atividades.

Nessa busca pela melhoria contínua, e por recursos financeiros extra orçamentários, o CHM submeteu uma proposta de projeto à Chamada Pública 01/2008 do Comitê do Fundo para o Setor de Transporte Aquaviário e Construção Naval (CT-AQUA), da Financiadora de Estudos e Projetos (FINEP). Foi contemplado com o financiamento de um projeto de desenvolvimento científico intitulado Sistema de Monitoramento e de Previsão Ambiental Portuário (SMAP). Ao submeter o projeto, o CHM visou desenvolver uma metodologia para a criação de um sistema de monitoramento e de previsão ambiental, voltado para as operações de aproximação e atracação em portos e, em contrapartida, obter mais equipamentos para o monitoramento de condições ambientais, além de capacitar seu pessoal em modelagem numérica costeira de forma operacional, tornando-se pioneiro na atividade no país. Assim sendo, ao contribuir para a melhoria das operações portuárias no país, o CHM também conseguiu ampliar sua capacidade para atender demandas já existentes nas atividades relacionadas à sua missão.

O SMAP idealizado provê informações ambientais observadas nas áreas adjacentes ao porto em tempo real e também previsões das condições ambientais para a localização do porto, no momento de atracação/desatracação. Adicionalmente, apresenta produtos específicos para o auxílio à decisão da praticagem e de autoridades portuárias que são disponibilizados no sistema.

Devido à localização do CHM, o porto do Rio de Janeiro foi escolhido como o sistema piloto do projeto, no intuito de adquirir os conhecimentos necessários para a sua implementação, oferecendo metodologia e suporte para as autoridades portuárias de outros portos que manifestem o interesse em implementação semelhante.

A execução do projeto se iniciou em dezembro de 2008 e teve seu término oficial em dezembro de 2014. O objetivo deste artigo é descrever, na visão gerencial, o desenvolvimento do projeto, bem como discutir algumas dificuldades, técnicas e logísticas, enfrentadas durante a execução, realizando uma análise crítica, como forma de aprendizado para projetos futuros.

\section{MATERIAIS E MÉTODOS}

O porto escolhido como piloto foi o do Rio de Janeiro, que está localizado no interior da Baía de Guanabara, em sua costa oeste. O acesso marítimo se inicia na entrada da Baía de Guanabara por um canal de acesso, com largura de $1,5 \mathrm{~km}$ e profundidade mínima de $17 \mathrm{~m}$, sendo delimitado pelos faroletes do Morro do Pão de Açúcar e da Fortaleza de Santa Cruz. A extensão total é de $18.500 \mathrm{~m}$, dos quais 11.100 metros cobrem a distância entre a parte externa da baía e os fundeadouros e os outros $7.400 \mathrm{~m}$, na direção norte, conduzem aos terminais privativos no interior da mesma [1].

A elaboração e execução do projeto seguiram o modelo de gerenciamento de projetos da FINEP, baseado em cronograma de execução de metas físicas e financeiras, bem como na liberação de recursos financeiros em parcelas de desembolso [4], sendo metas e desembolsos 
definidos pela FINEP, em conjunto com a equipe de planejamento do CHM. O projeto foi executado pela equipe técnica do CHM e por profissionais de empresas especializadas, que foram contratadas ao longo da execução do mesmo. O acompanhamento das atividades foi realizado através de relatórios, técnico e financeiro, periodicamente enviados à FINEP [4], contendo: os resultados dos indicadores de desempenho; a relação de material adquirido; relatórios de atividades realizadas; e tabelas de controle e detalhamento de gastos.

Foram realizados estudos prévios para: definir: quais as quantidades e locais para estações de monitoramento; como configurar a representação da Baía de Guanabara no modelo numérico de previsão; quais os parâmetros ambientais importantes para a navegação e para a atracação/desatracação; e quais ferramentas de auxílio à decisão confeccionar. Neste processo foram utilizadas todas as informações ambientais e pesquisas disponíveis sobre a Baía de Guanabara na comunidade científica, bem como visitas técnicas e de levantamento de campo que se fizeram necessários. A execução do projeto será relatada nas seções seguintes.

\subsection{AQUISIÇÃo, INSTALAÇão DE EQUIPAMENTOS E COLETA DE DADOS DE MONITORAMENTO}

A meta física "Aquisição, instalação, manutenção e operação de sensores e equipamentos meteoceanográficos", bem como a meta "Monitoramento, análise e tratamento dos dados coletados" são referentes aos equipamentos de coleta de dados e ao monitoramento ambiental. Foram escolhidos como indicadores dessas metas físicas apresentar os dados e obter séries temporais, respectivamente.

Os equipamentos que integram o sistema de monitoramento foram definidos pelos técnicos envolvidos na elaboração da proposta do projeto, baseando-se nos estudos realizados pela equipe de planejamento. Cabe ressaltar que a proposta inicial não foi totalmente financiada pela FINEP, fazendo com que a equipe executora fizesse novos estudos e adaptações, adequando as necessidades aos recursos financeiros disponibilizados. Os equipamentos utilizados no projeto foram estações meteorológicas automáticas, estações maregráficas, também automáticas, e ADCP (Acoustic Doppler Current Profiler). As estações meteorológicas coletam informações dos parâmetros atmosféricos; as maregráficas, de elevação do nível d'água; e os ADCP, de corrente, elevação do nível d'água e ondas.

Após a compra dos equipamentos, foram avaliadas as localizações ideais para instalação, de forma que as informações geradas fossem mais representativas possível da área de aproximação ao porto, e que oferecessem facilidades logísticas de acesso, manutenção e possibilidades de transmissão remota dos dados. Como resultado desse estudo, foram definidas estações fixas de monitoramento e campanha de coleta de dados.

Ao fim de cada instalação e campanha de coleta de dados procedia-se a análise e o tratamento dos dados coletados.

\subsubsection{As Estações Fixas}

Como estações fixas de monitoramento foram definidas duas estações meteomaregráficas (um conjunto, com estação meteorológica e maregráfica), uma na Ilha Fiscal e outra na Ilha Rasa (Figura 1). Os locais foram escolhidos por possibilitarem o monitoramento ambiental no exterior e no interior da baía, apresentando apoio logístico de organizações militares no local. $\mathrm{O}$ método de transmissão escolhido, através de testes realizados no período de estudo, foi via rádio, por não gerar custo de operação após o encerramento oficial do projeto. 


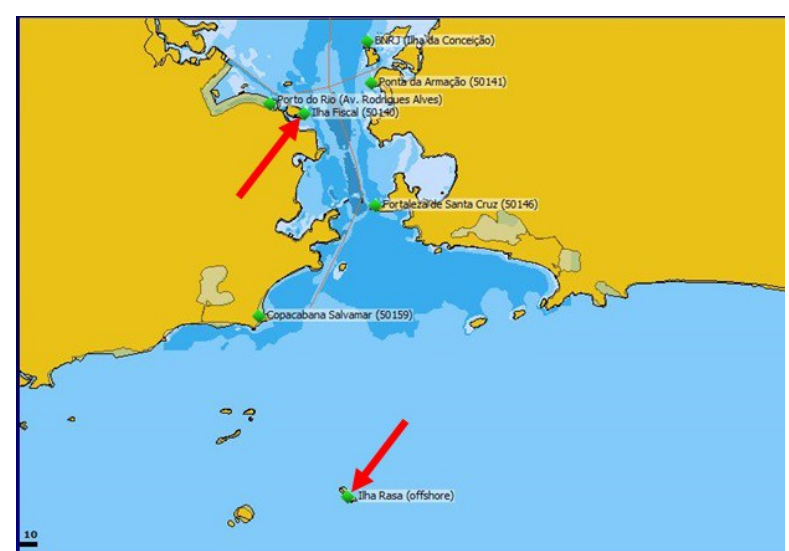

Figura 1: Localização das estações fixas

\subsubsection{As Campanhas de Coleta de Dados}

Não foi possível adotar a mesma estratégia de estação fixa de monitoramento para os $\mathrm{ADCP}$, tendo em vista que os mesmos devem ser fundeados, isto é, presos no fundo do mar, para realizar a coleta [10]. Desta forma, a logística de manutenção e recarga de bateria dependeria de embarcações em prontidão para realizar o serviço. Optou-se pela realização de campanhas periódicas de coleta de dados.

Com o sistema de campanha, embarcações que estivessem saindo/regressando de comissões programadas poderiam realizar o lançamento/recolhimento dos equipamentos. Porém, os pontos de fundeio foram fixados, no intuito de gerar uma continuidade na série de dados e possibilitar o estudo do comportamento das correntes, elevação do nível d'água e ondas. Os locais escolhidos para fundeio foram próximo à boia de sinalização da margem leste do canal varrido (canal de entrada da baía) e próximo à boia de sinalização de Cotunduba (Figura 2). As localidades foram escolhidas por possibilitarem o monitoramento ambiental no interior e no exterior da baía, com a vantagem logística de não oferecerem perigo de arrasto ou danos aos equipamentos provocados por navios de passagem, devido à presença das boias de sinalização. Os fundeios nos dois pontos foram realizados simultaneamente e os períodos de coleta foram escolhidos de forma a obter informações ambientais para todas as estações do ano.

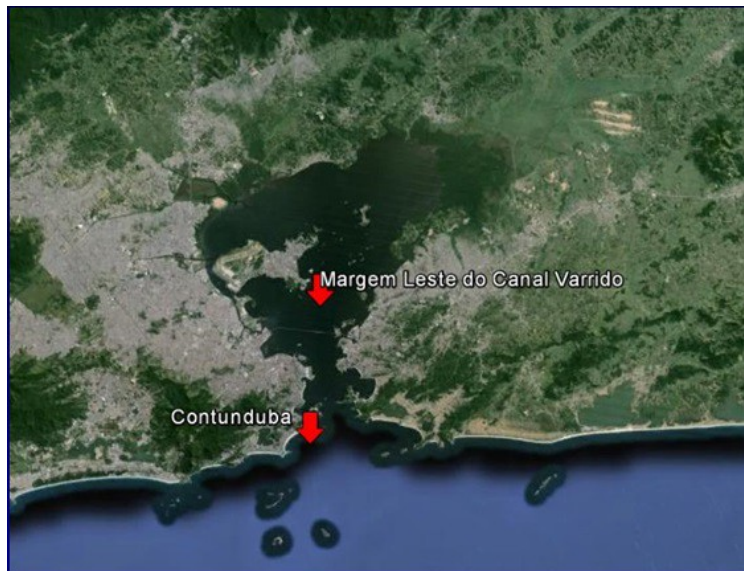

Figura 2: Localização dos fundeios (a) e fotos de um dos fundeios que foi realizado (b)

\subsection{CONFIGURAÇ̃̃o do SISTEMA}

As metas físicas "Implementação do sistema de monitoramento e previsão ambiental" e "Desenvolvimento de sistemas de alerta para monitorar de forma sinótica eventuais acidentes ambientais" são referentes à confecção do sistema integrado, o SMAP completo, e à produção dos auxílios à decisão. Foram escolhidos como indicadores dessas 
metas os resultados e saídas do próprio sistema, bem como relatórios técnicos de análise desses resultados.

Dentre os softwares pesquisados para servir de base para o SMAP, o pacote computacional Delft3D-FEWS foi o que mais se adequou às necessidades do projeto, pois possibilita realizar as previsões para a área do porto e também apresentar os dados do monitoramento, bem como apresentar uma comparação entre a previsão e o dado observado, isto é, no momento em que a previsão se torna passado, pode-se comparar a mesma com o dado de monitoramento para o mesmo data-hora. Além disso, pode-se realizar uma correção da previsão baseando-se no dado observado. Uma descrição mais detalhada pode ser encontrada em [2].

Para gerar as previsões foi preciso configurar um modelo matemático (a modelagem numérica) que representasse a Baía de Guanabara e seus mecanismos internos. Para a confecção dos auxílios à decisão às atividades portuárias, e para a preparação do SMAP a fim de fornecer informações para os casos de acidentes ambientais, foi necessário o levantamento de informações técnicas sobre cada um dos eventos.

Para a instalação do software realizou-se uma reestruturação física e lógica no CHM, que contou com a aquisição de servidores de cálculo com dedicação exclusiva para o sistema; estações de trabalho para a recepção e o tratamento dos dados; reestruturação da rede lógica e de cabeamentos; aquisição de equipamentos e contratação de serviços para fornecimento de energia ininterrupta; e investimentos em segurança da rede, com o intuito de garantir o perfeito funcionamento do SMAP.

\subsubsection{Configuração da Modelagem Numérica}

No pacote computacional Delft3D-FEWS, o módulo Delft3D-FLOW realiza a modelagem hidrodinâmica (referente à dinâmica do oceano). Maior detalhamento sobre o modelo numérico Delft3D-FLOW pode ser encontrado em [3].

$\mathrm{Na}$ representação da Baía de Guanabara no SMAP, foram utilizados dados de cartas náuticas, e de banco de dados de levantamentos batimétricos, para descrever o fundo, isto é, confeccionar a batimetria para o modelo (Figura 3). As profundidades (iniciando na superfície livre até o fundo) foram divididas em dez camadas sigma (a coordenada vertical sigma acompanha os contornos de relevo/batimetria [5]). O domínio para essa modelagem (área onde são realizados os cálculos) foi dividido horizontalmente em 244 pontos de grade no eixo x por 241 pontos de grade no eixo y, com o espaçamento variando entre $20 \mathrm{~m}$ (no interior da baía e na região próximo à entrada) e $6000 \mathrm{~m}$ (pontos mais próximos das bordas do domínio) (Figura 3).

Como informações externas ao domínio (condições de contorno), foram utilizadas as saídas de Temperatura da água, Elevação do nível d'água e Salinidade de outro modelo hidrodinâmico, o HYCOM (Hybrid Coordinate Ocean Model), com resolução espacial de 1/24 do grau e temporal de uma hora. As informações de Elevação do nível d'água do HYCOM são passadas para o domínio através da função invariante de Riemann (Equação 1) [6]. Essa metodologia foi adotada devido ao fato das previsões do HYCOM incluírem a contribuição da maré em suas previsões, considerando assim uma fronteira aberta e não reflexiva [6].

$$
f(t)=U+\zeta \sqrt{\frac{g}{d}}
$$




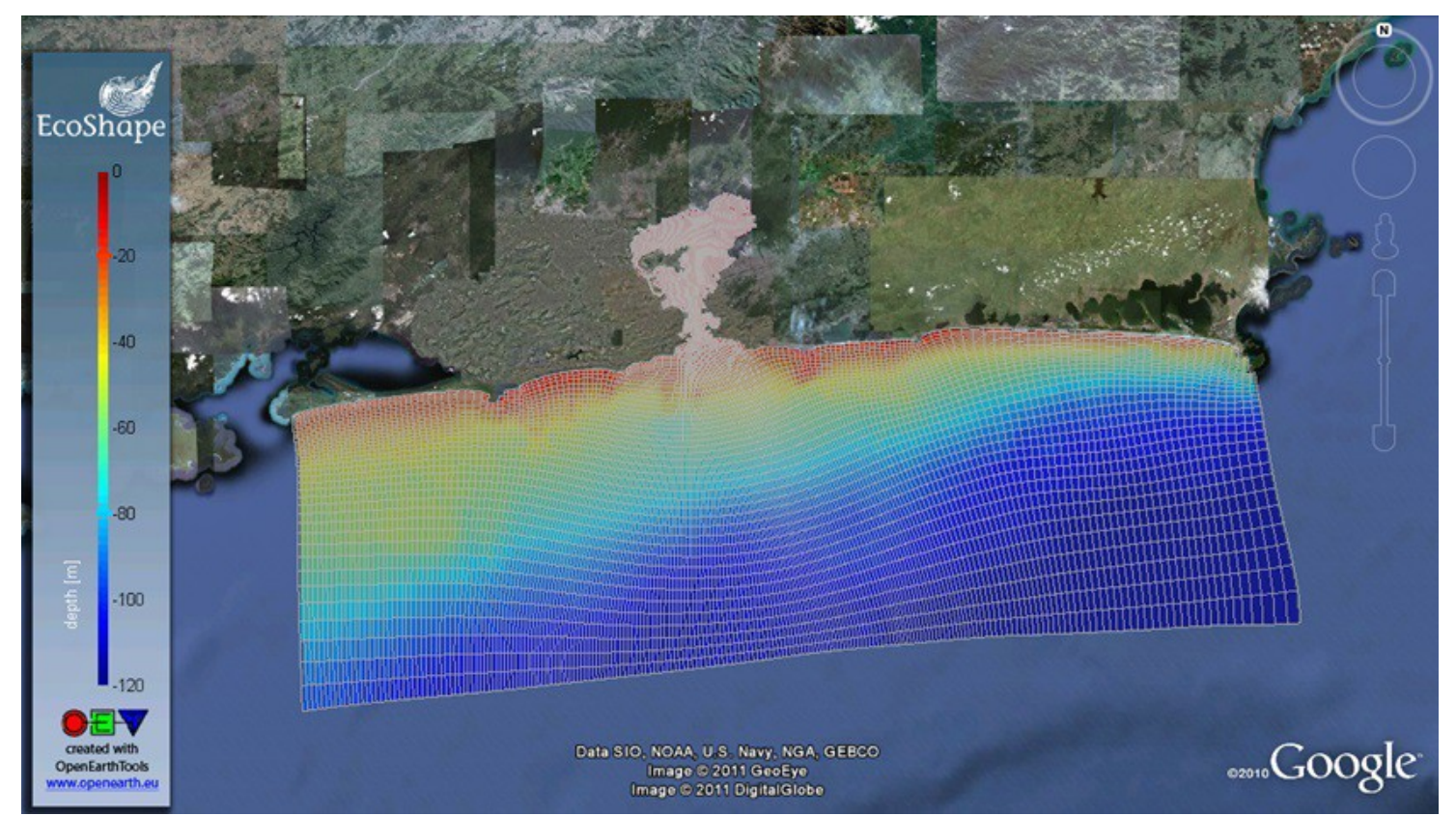

Figura 3: Superfície batimétrica (cores) com a grade de modelagem hidrodinâmica sobreposta (linhas brancas)

As bordas do domínio foram divididas em onze segmentos à oeste, doze segmentos à leste e dezesseis segmentos ao sul (Figura 4), pontos de entrada para as informações do HYCOM no domínio.

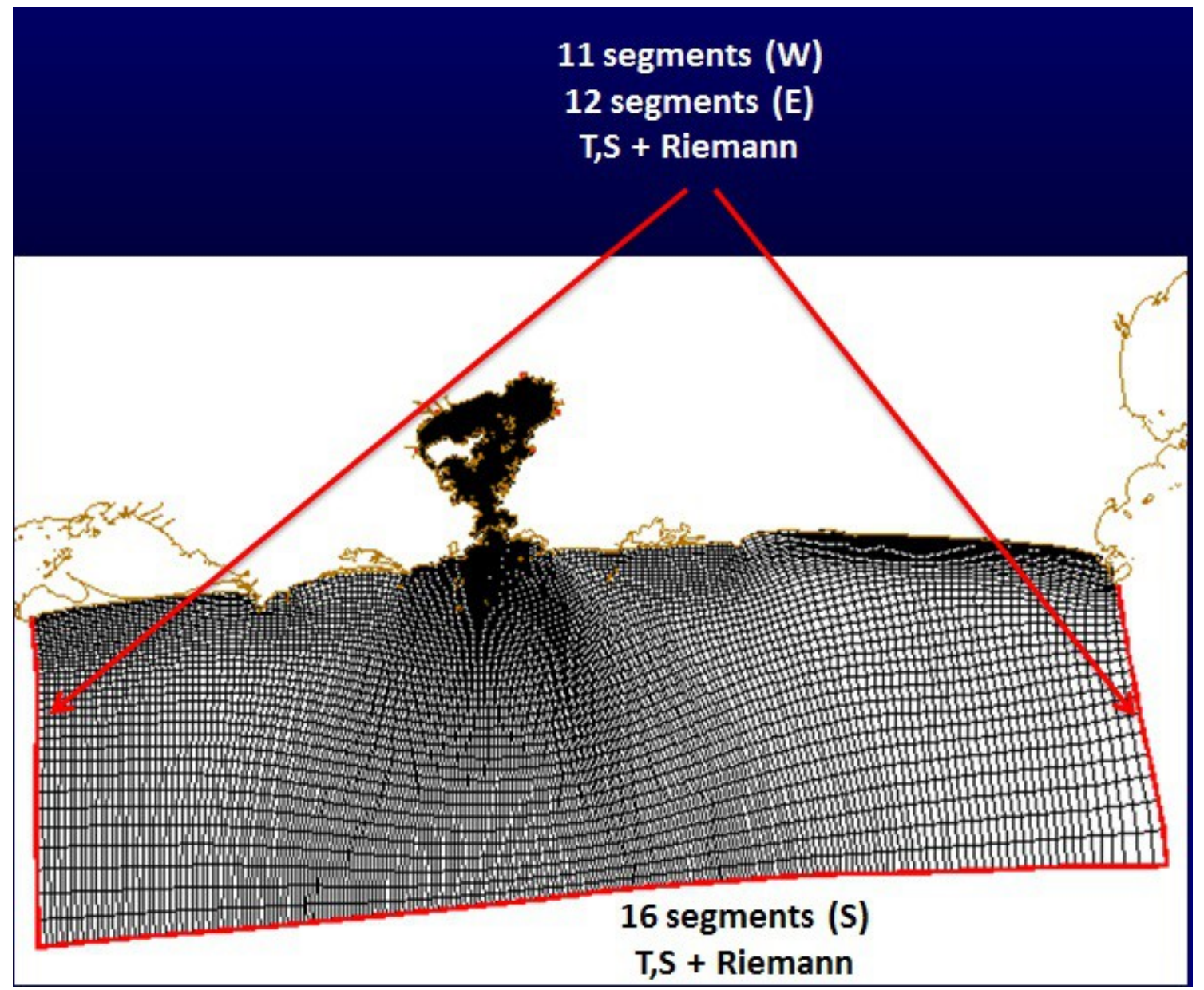

Figura 4: A grade de modelagem, com suas bordas, o número de segmentos em cada borda e quais as variáveis inseridas no segmento. 
Além das entradas para os dados do HYCOM, na área interna da baía foram consideradas as entradas das vazões de nove rios (as principais contribuições) [11].

Para a modelagem de ondas (propagação do espectro de ondas), o pacote apresenta o modelo numérico Delft-WAVE, uma adaptação do modelo SWAN (Simulating Waves Nearshore), que é amplamente utilizado na comunidade científica. Maior detalhamento sobre o modelo Delft-WAVE pode ser encontrado em [3].

Foram construídas duas grades de modelagem, que rodam juntas, uma com melhor resolução no interior da baía e outra menos resolvida na parte externa (Figura 5), sendo que as resoluções são melhoradas, uma a partir da outra, iniciando com a resolução do modelo de ondas operacional no CHM, WAVEWATCH III (modelo de ondas amplamente utilizado na comunidade científica), que fornece as condições de contorno para a modelagem no SMAP.

A partir do resultado de cada célula do modelo WAVEWATCH III operacional são geradas séries temporais de altura significativa das ondas, direção e período, que são passadas para o domínio externo. Os domínios, externo e interno, têm suas previsões geradas simultaneamente.

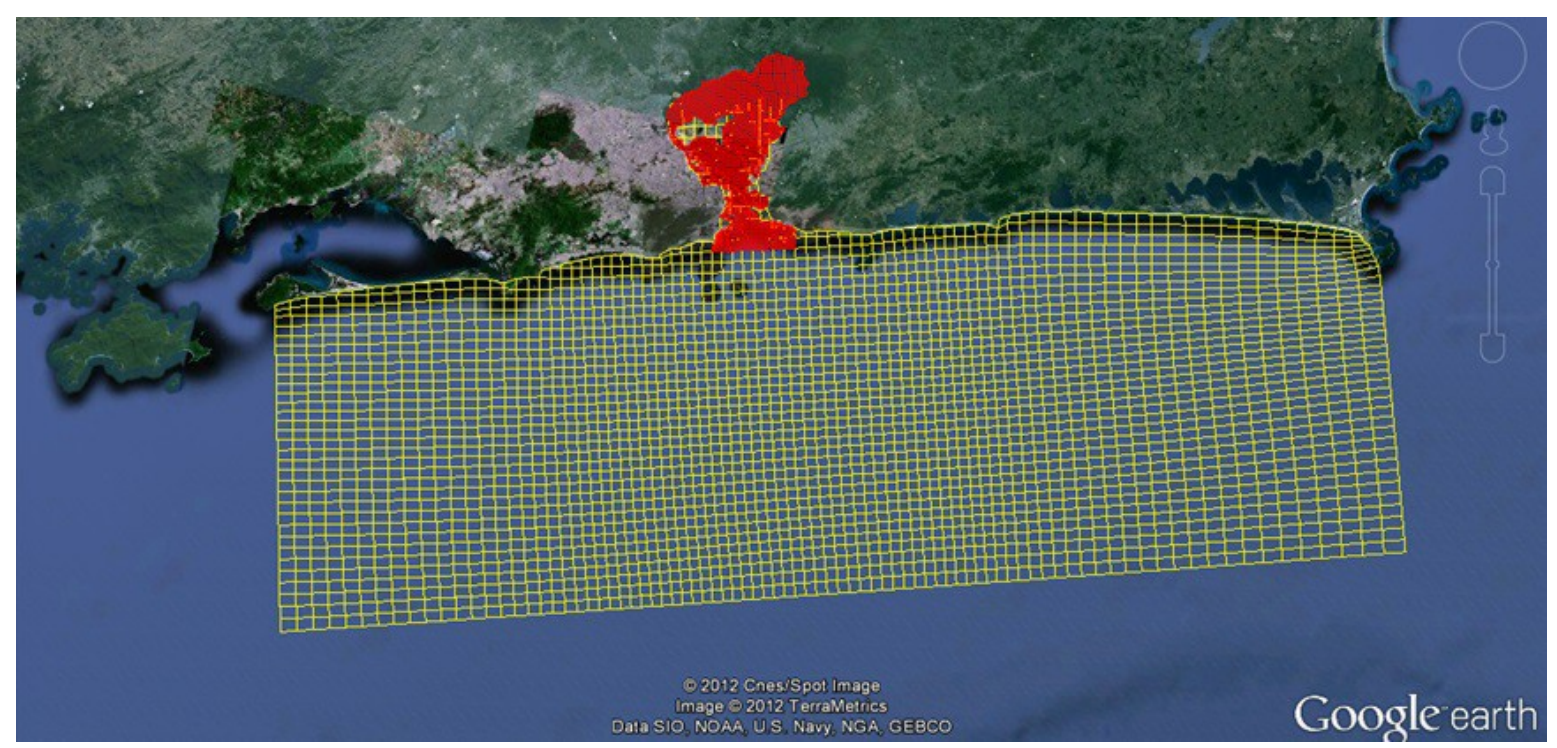

Figura 5: Grades interna (vermelha) e extrena (amarela) da modelagem de ondas do SMAP

As condições atmosféricas, utilizadas como forçante para o SMAP (tanto para a modelagem hidrodinâmica quanto para a modelagem de ondas), são provenientes do modelo atmosférico operacional no CHM e em caso de falha, como opcional, o modelo atmosférico de livre distribuição do NCEP (National Centers for Environmental Prediction), com os parâmetros vento e pressão atmosférica. Os parâmetros são fornecidos pelas células do modelo atmosférico que se localizem dentro do domínio do SMAP.

A partir da modelagem numérica construída são geradas as previsões das variáveis ambientais para a área portuária do Rio de Janeiro.

\subsubsection{Informações para a Confecção dos Auxílios à Decisão e Preparação para o Caso de Acidente Ambiental}

A partir das previsões geradas pelo SMAP e dos dados de monitoramento, foi possível gerar auxílios à decisão para as operações portuárias.

Um dos auxílios criados foi o alerta para o nível de navegação segura. Segundo [8] a lazeira mínima de água que se deseja ter abaixo da quilha quando na navegação pode ser aproximada pela profundidade dada pelo calado, somado de dois metros ou $15 \%$ do valor do calado, quando o mesmo for muito maior do que dois metros. Considerando essa condição, foi elaborado um alerta para os pontos de verificação (previamente escolhidos), quando a previsão de nível d'água atinja valores inferiores a cinco metros de profundidade. O alerta é 
indicado no sistema por ícones especiais na área gráfica e faixas delimitadoras no caso das séries temporais.

Outro auxílio à decisão elaborado foi o cálculo e a visualização do vetor corrente transversal à derrota de entrada pelo canal varrido e ao deslocamento leste-oeste para os portos do Rio de Janeiro e Niterói, possibilitando a verificação da presença de correntes mais fortes que forem perpendiculares ao movimento das embarcações, prevenindo possíveis balanços prejudiciais aos navios.

Como preparação para casos de acidentes ambientais, as previsões geradas pelo SMAP fornecem parâmetros suficientes para: realizar o cálculo de calado dinâmico; utilizar como condição inicial e forçante para simulações de derramamento de óleo (em softwares específicos para o mesmo); e em estudos de qualidade da água (em softwares específicos para tal propósito, sendo que o próprio pacote Delft3D-FEWS oferece essa ferramenta).

Com o monitoramento definido e o sistema configurado foi possível realizar testes de funcionamento do SMAP. Os resultados serão demonstrados a seguir.

\section{RESULTADOS}

Mesmo sem o financiamento integral da proposta inicial, o projeto propiciou a aquisição de duas estações meteorológicas, três estações maregráficas e complementou os recursos financeiros para a aquisição de dois $\mathrm{ADCP}$, além da aquisição de peças sobressalentes dos equipamentos mais sensíveis e imprescindíveis. Também proporcionou melhorias na infraestrutura lógica da rede em operação no CHM, bem como a aquisição de equipamentos que ampliaram a capacidade em gerenciá-la. Tais aquisições contribuíram indiretamente para melhorar o atendimento de algumas demandas do Serviço Meteorológico Marinho, atividade que o CHM exerce em prol da sociedade.

Algumas dificuldades logísticas, que serão detalhadas na análise crítica, impossibilitaram que a instalação da estação meteomaregráfica na Ilha Rasa fosse concluída e somente a parte meteorológica foi instalada.

A instalação e a transmissão dos dados da estação meteomaregráfica da Ilha Fiscal foi concluída, as séries temporais analisadas, mas foi constatado que a operação apresentou falhas. A causa apontada pela empresa responsável foi a falta de aterramento, que realizou estudo de sanar o problema constatado.

Com os ADCP foram realizadas duas campanhas de coleta para os dois pontos predefinidos simultaneamente, uma no verão e outra no inverno. Os dados coletados foram analisados e tratados. Com esses dados foi possível iniciar uma caracterização do regime de ondas e correntes para a Baía de Guanabara, sendo necessário realizar campanhas de coleta nos períodos de primavera e outono para a conclusão dessa caracterização.

Em prol da atividade portuária, a previsão construída especificamente para a área do porto, conforme ilustrado na figura 6 , confere mais confiança à informação para a praticagem. As verificações iniciais sugerem que o prognóstico gerado pelo SMAP apresenta os padrões esperados para a área da Baía de Guanabara (Figura 7 e 8).

Os auxílios à decisão desenvolvidos seguem ilustrados nas figuras 9 e 10 . O alerta de nível de navegação segura é de fácil visualização e entendimento, apresentando-se como uma ferramenta útil e de rápida análise (Figura 9). O auxílio à decisão de corrente transversal ao movimento apresenta setas que indicam a intensidade e direção da corrente (Figura 10), sendo fácil entendimento para o navegante e tornando possível identificar os períodos com menor intensidade das correntes e as direções, o que facilita o deslocamento das embarcações. 


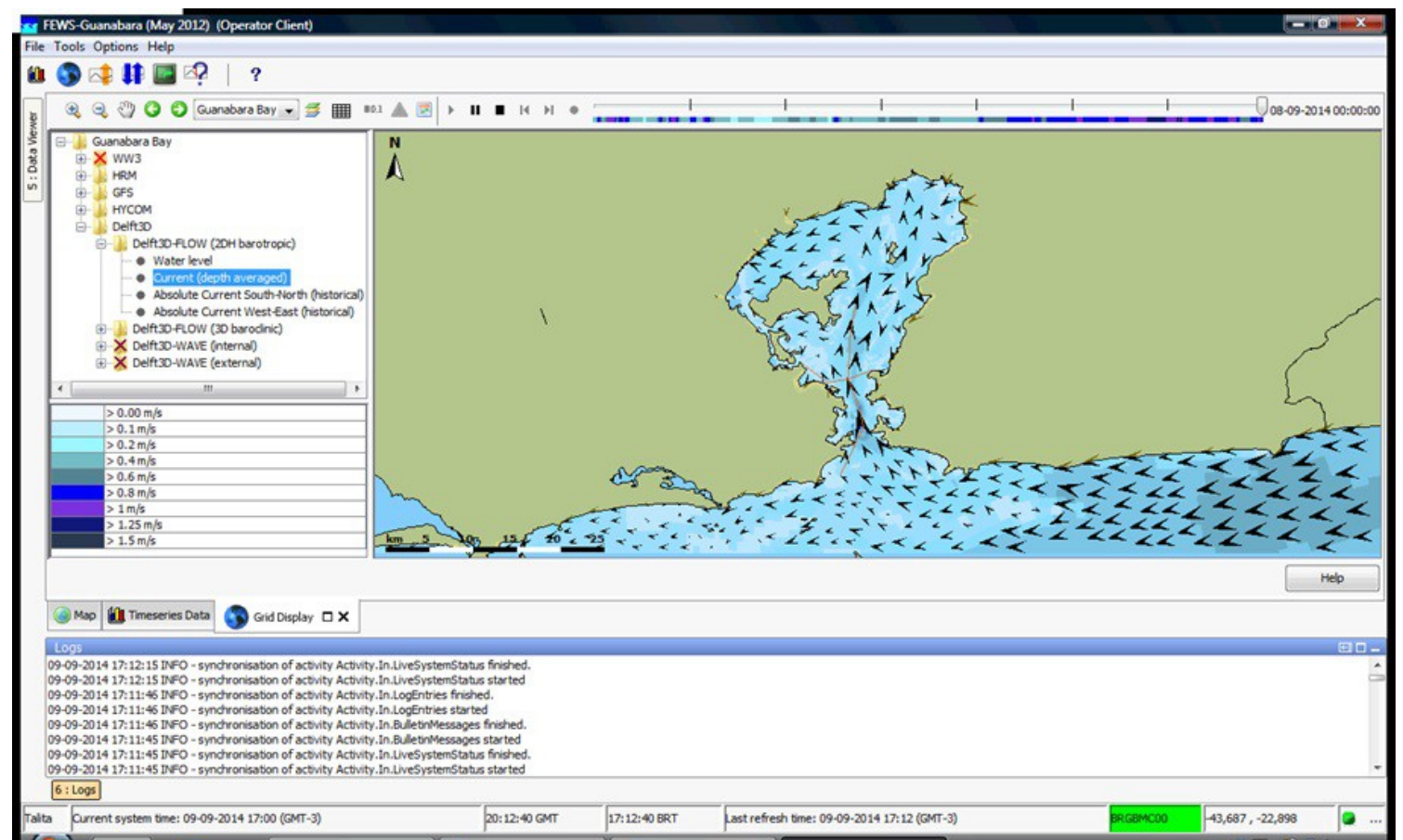

Figura 6: tela de visualização do SMAP com a previsão de corrente à superfície

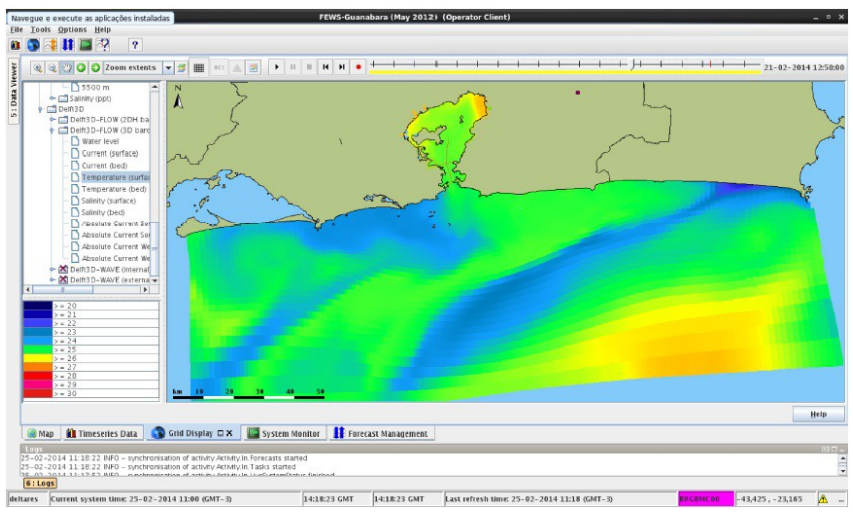

(a)

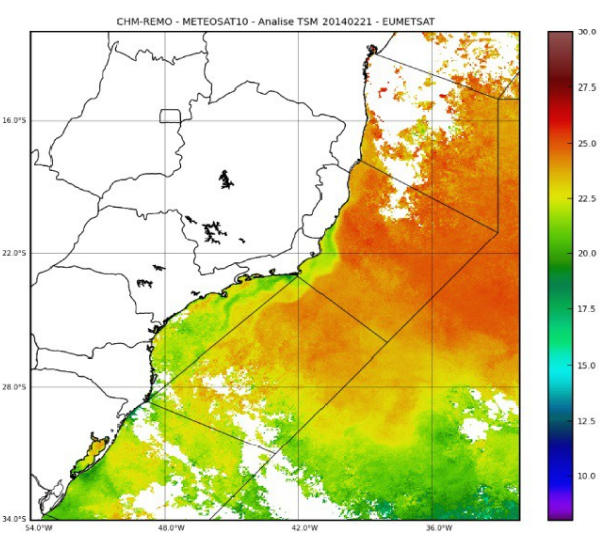

(b)

Figura 7: Comparação da previsão de Temperatura da Superfície do Mar (TSM) do SMAP (a) e dados de TSM de satélite (b). Nas imagens é possível verificar a semelhança na distribuição da TSM prevista e observada, na área junto à costa do Rio de Janeiro.

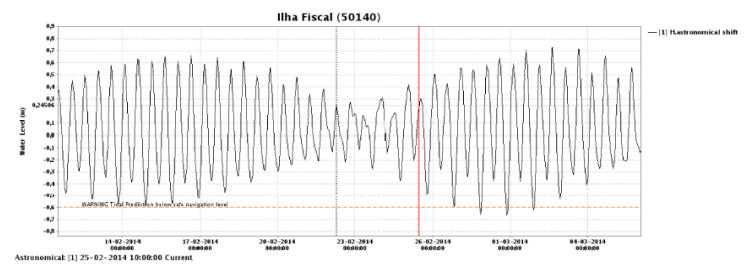

(a)

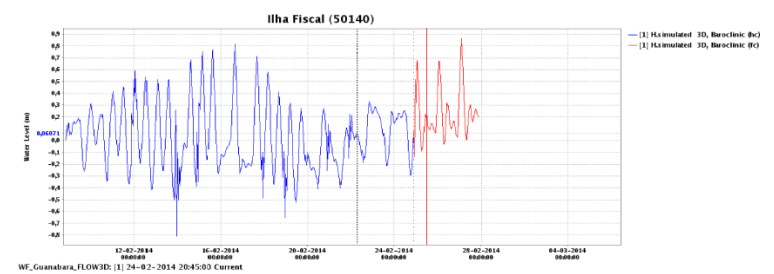

(b)

Figura 8: Comparação da previsão astronômica de nível do mar (a) e a previsão do SMAP (b). É possível observar o comportamento semelhante das curvas no período entre as linhas verticais preta e vermelha. 


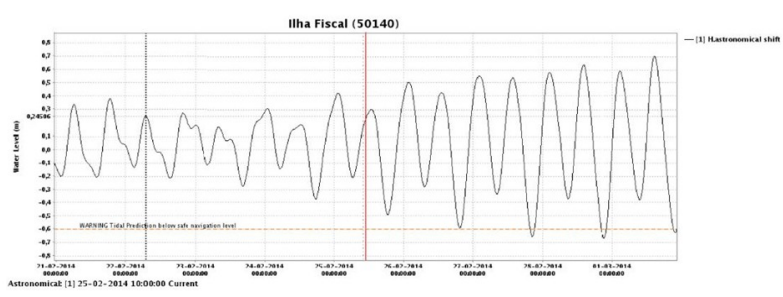

(a)

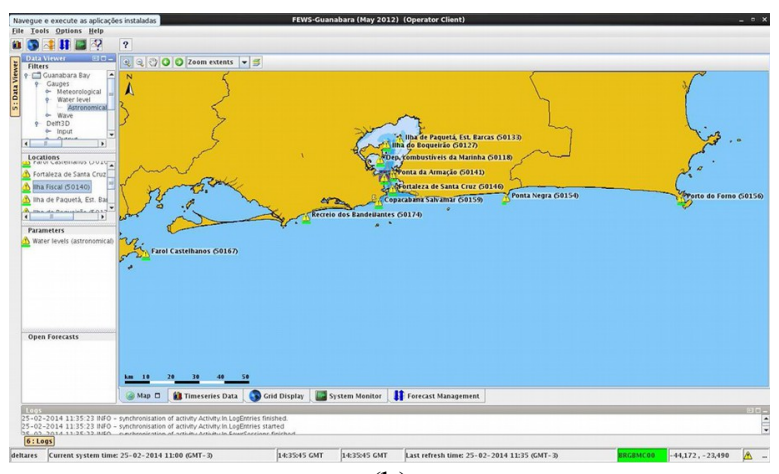

(b)

Figura 9: Auxílio à decisão de previsão abaixo do nível de navegação segura indicado como uma linha vermelha na série temporal (a) e como ícone especial (!) na estação que apresenta tal previsão (b).

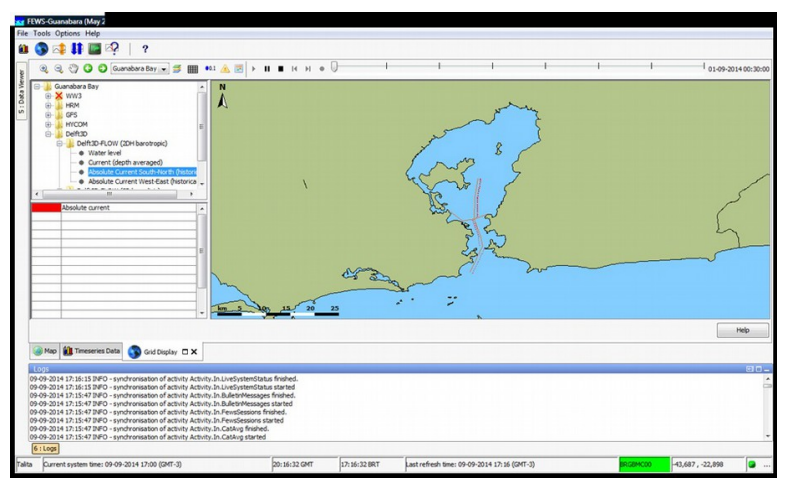

(a)

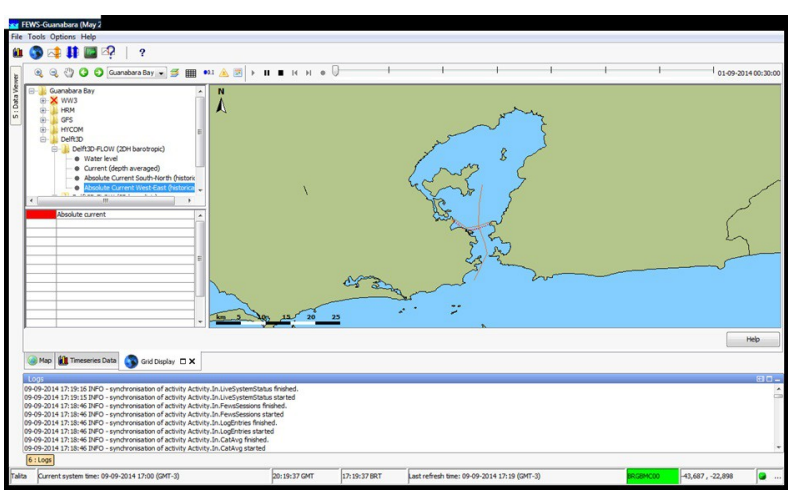

(b)

Figura 10: Auxílio à decisão de previsão da corrente transversal ao deslocamento no canal varrido (a) e transversal ao deslocamento Rio de Janeiro-Niterói (b).

Devido a problemas de hardware, os servidores exclusivos para o funcionamento do SMAP apresentaram defeito e a situação do sistema deixou de ser operacional. Manutenções no sistema ainda serão finalizadas no intuito de tornar o SMAP novamente operacional.

\section{DIFICULDADES ENCONTRADAS}

Conforme já exposto nos resultados, a estação fixa da Ilha Rasa ainda não está em total funcionamento, devido a dificuldades logísticas de acesso à ilha, que dependiam de embarcação e não ocorreram conforme previsto na fase de planejamento.

Um dos fatores que contribuiu para os problemas no andamento desta atividade foi o atraso, em um ano, na liberação da segunda parcela de desembolso, ocasionando a demora na contratação de serviços essenciais para a instalação da estação. Outro fator foi o longo período inoperante de embarcações adequadas para fazer o apoio logístico de desembarque de material e equipamentos. O primeiro acabou contribuindo para que o andamento das atividades sofressem com o segundo, uma vez que no período previsto para a liberação dos recursos financeiros, tais embarcações se encontravam em operação.

$\mathrm{Na}$ tentativa de contornar as dificuldades em encontrar uma embarcação apropriada para realizar a tarefa, e que estivesse em operação, a equipe executora do projeto buscou fazer uso de embarcações de maior porte para concluir a atividade. Essa alternativa acrescentou outras dificuldades logísticas, devido ao fato de embarcações de maior porte não conseguirem se aproximar da ilha para realizar o desembarque de material. Foi necessário fazer o desembarque com o uso de botes, tornando a atividade arriscada, por se tratar de equipamentos sensíveis e cujo valor não poderia ser ignorado. As fotos da figura 11 ilustram 
as dificuldades logísticas de acesso à ilha.

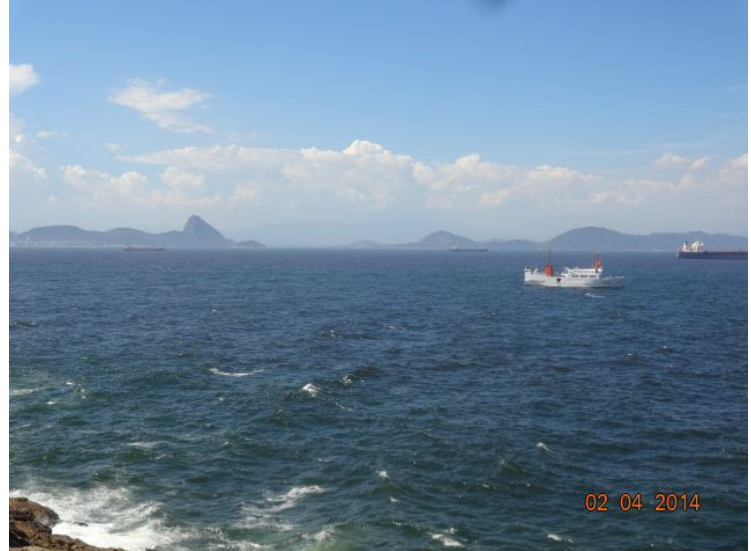

(a)

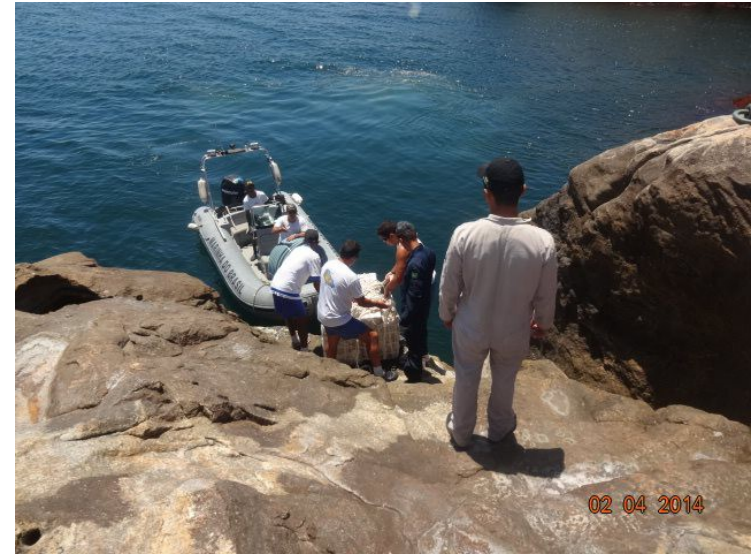

(b)

Figura 11: Fotos da embarcação de maior porte e sua distância da ilha (a) e do desembarque de equipamento com o bote (b).

Apesar do atraso, foi possível realizar o desembarque de todos os equipamentos da estação meteomaregráfica e todo o material necessário para a instalação.

Mesmo com todo o material no local de destino, ainda houve dificuldade em instalar a parte maregráfica. $\mathrm{O}$ problema estava em encontrar um ponto, nas encostas da Ilha Rasa, mais abrigado da ação destrutiva de ondas, que geralmente atingem os limites da ilha com muita força em situação de mau tempo. Diversas tentativas de verificação de local apropriado foram frustradas.

Com todas as dificuldades enfrentadas foi possível concluir que, apesar de apresentar apoio de organização militar, a logística de abrigar a estação meteomaregráfica na Ilha Rasa foi subestimada e que alguns fatores não foram cuidadosamente analisados no planejamento.

Outro aspecto negativo no planejamento e desenvolvimento do projeto foi a inclusão dos recursos provenientes do financiamento da FINEP na execução financeira da Marinha do Brasil (MB), amarrando assim o período para a liquidação dos recursos financeiros ao exercício financeiro da $\mathrm{MB}$ e não ao prazo de um ano a partir da liberação da parcela de desembolso. Com esse procedimento adotado também não foi possível utilizar os rendimentos das aplicações financeiras em prol do projeto, prática comum em projetos que possuem conta bancária exclusiva.

Além das dificuldades com relação aos recursos financeiros, os encargos administrativos acabaram acumulados pela equipe executora, juntamente às tarefas técnicas. Como aprendizado pode-se destacar que formas alternativas para administração dos recursos financeiros, como a inclusão de um interveniente, podem trazer muitos benefícios na execução do projeto.

\section{PERSPECTIVAS}

O CHM ainda está aplicando recursos humanos e financeiros para que o SMAP se torne plenamente operacional e venha contribuir para as atividades portuárias, bem como para o Serviço Meteorológico Marinho.

\section{CONCLUSÕES}

A execução do projeto rendeu benefícios materiais e ampliou a capacitação do pessoal do CHM, ampliando também a capacidade em atender as demandas de suas atividades, além de manter o CHM na busca pela excelência.

As dificuldades enfrentadas durante o período de execução serviram como 
aprendizado para futuros projetos e para ajustes na metodologia de configuração de um sistema como o SMAP.

Apesar de não estar operacional, o SMAP é uma realidade para o CHM. O sistema é capaz de gerar previsões costeiras e também propiciar a obtenção de dados de ondas e correntes no interior da Baía de Guanabara, medições de grande importância devido à escassez desse tipo de informação na região.

\section{REFERÊNCIAS BIBLIOGRÁFICAS}

[1] Agência nacional de Transporte Aquaviário (ANTAQ). Porto do Rio de Janeiro. Disponível em: < $\quad$ http://www.antaq.gov.br/portal/pdf/Portos/2012/RioJaneiro.pdf $>$. Acesso em 06 mar 2015.

[2] Deltares.

Delft-FEWS.

Disponível

em:

$<$ http://oss.deltares.nl/c/document library/get file?uuid=bf86fd5e-50d5-4188-832c3d46b5ae61a5\&groupId=145641>. Acesso em 06 mar 2015.

[3] . Manuals. Disponível em: $<$ http://oss.deltares.nl/web/delft3d/manuals $>$. Acesso em: 06 mar 2015.

[4] Financiadora de Estudos e Projetos (FINEP). Formulários e Manuais. Disponível em:< http://www.finep.gov.br/pagina.asp?pag=clientes formularios manuais $>$. Acesso em 06 mar 2015.

[5] Holton, J. R.,1992. An Introduction to Dynamic Meteorology, $3^{\text {a }}$ edição.

[6] Jacobs, R. P. M., 2010. Non-hydrostatic computations of nearshore hydrodynamics. M.Sc. Thesis Delft University of Technology

[7] Manual da Qualidade do Centro de Hidrografia da Marinha.

[8] Miguens, A. P., 1996. Navegação: A ciência e a arte. Volume I - Navegação Costeira, Estimada e em Águas Restritas. Capítulo 7. 7.1 Conceito de Navegação de Segurança. p. 185-194. Diretoria de Hidrografia e Navegação.

[9] Ordens do Comandante da Marinha 2014.

[10] TELEDYNE - RD Instruments (RDI), 2006. Acoustic Doppler Current Profiler Principles of Operation: A Practical Primer.

[11] Malta, F. S., 2005. Estudo de Correntes de Maré do Complexo Estuarino da Baía de Guanabara - RJ. Estudo realizado pela empresa Tetra Tech, responsável pela confecção da modelagem numérica. 